\title{
Learning Sports Management with e-Learning Tools.
}

http://dx.doi.org/10.3991/ijet.v8i4.2505

\author{
Sara Redondo, Ana María Villalba, Álvaro Merino Jiménez \\ Universidad Europea Madrid, Madrid, Spain
}

\begin{abstract}
Nowadays, hybridity is in demand from students in university degrees. They expect to be able to choose between on campus courses and online courses depending on their needs and wishes. Motivated by this, since academic year 2010-2011, the Universidad Europea de Madrid offers some of its traditional on campus undergraduate and graduate programs also in an on line format, under the concept of Universidad Personal. One of these programs, the MBA Master's Degree in Sports Management, was selected as the runner-up in the e-learning category of the 2012 International E-Learning Award (Academic Division), given by the International E-Learning Association. The purpose of this paper is to describe in more detail the objective and structure of this program, as well as the pedagogical and product model in which is based on, showing the different elements used for its design.
\end{abstract}

Index Terms-e-learning, pedagogical model, online product model, virtual subject, SCORM.

\section{INTRODUCTION}

Until the end of the eighties, graduate programs in sports management were not offered. Many of these programs were very unspecific, namely courses that only involved different areas related to physical activity and sport.

Several reasons justify the need for a specialization in this field of knowledge and, consequently, the design of a master degree, that meets the demands existing in the market. These include:

- The growing role played by public institutions in the promotion of sport, which had as a consequence, on the one hand, the creation of a wide network of public sports facilities and, on the other hand, the development of sports competitions in the autonomous and municipal administrations. Due to the institutional demands, sports management has been incorporated as a new professional area.

- The increasing proliferation of companies that offer private sports services in order to meet the growing social demand. This has generated a new professional scenario, which requires knowledge in sports, and also in management. There exist a niche market for the creation of enterprises and private business than can promote the self-employment, as well as the recruitment, of new professionals.

- The progressive growth of sports practice and the popular interest in competitive sports, especially in television and the Internet, has risen very significantly the socio-economic impact of these activities.
- The great expansion in the supply of physical activity aimed at improving the quality of life, has made proliferate a large number of sports centers, gyms and stores dedicated to the practice of "sport-health". In the last years it has appeared an added demand in the management of private centers, similar to the development of the public sector since the eighties and nineties.

- The growth of sports event with follow-up at the global level involving great media impact to the organizing location, as well as an economic impact in the rest of the community.

- The emergence and growing importance of management, direction and organization of the sports as a field of specialization has been stated in different papers, focused on analyzing the labor market of the Bachelor of Physical activity and sport science.

Students enrolled in this program came from different areas of knowledge, being the most frequent: Administration and business management, Physical activity and sport science, Law, and Marketing and communication. The profile of this student is a professional with one to three years of experience in his/her areas of origin. The nexus of all of them is the passion for sport and the desire to be able to develop their knowledge in the sport area.

The emergence and growing importance of management, direction and organization of the sports as a field of specialization has been stated in different studies focused on analyzing the labor market of the Bachelor of Science, physical activity and sport in Spain. Thus, the position of the sports manager has been studied: features, skills, responsibilities, training needs, implications of his/ her work, etc. (Rodríguez, Boned, Mayorga, Merino, 2005).

Following, it is described the objectives and structure of MBA Master's Degree in Sports Management.

\section{OBJECTIVES AND STRUCTURE OF MBA MASTER'S DEGREE IN SPORTS MANAGEMENT}

The objective of MBA Master's Degree in Sports Management is to train management professionals in the world of sport. It is particularly suited to graduates who wish to update their knowledge and to professional athletes who, having reached the end of their playing career, aspire to continue their activities in the sports arena as managers. 
The international nature of this program enables the student and sports manager to obtain the broadest possible outlook regarding the different sports management models that exist, not only in Spain, but also beyond our borders, thanks to the participation of top-class international teaching staff. This training commitment will exponentially improve the field of vision and professional possibilities of our students.

The mission of the Sports Management MBA through the course of its studies is as follows:

- To acquire the knowledge that an MBA offers, aimed at the world of sports management.

- To expand knowledge and personal initiative, in order to improve the business world through sports.

MBA Master's Degree in Sports Management primarily consists of ten modules on company management. Subsequently, a cross-sectoral module is taught on management skills. The program contains a segment that specialises in sport and focuses on marketing, management and the operation of sports facilities. The training program counts for 60 ECTS credits (each subject has 6 ECTS credits). The subjects are the following:

\section{- General Management in Sports Organizations}

The subject on General Management is central to the MBA in Sports Management program. Throughout this subject, students are introduced to the knowledge and practice of executive, communicative and overall management skills which will allow them to develop their own management style from ethical planning, innovation and diversity management.

\section{- Accounting and Finance}

Accounting and finance are fundamental tools for making decisions in the field of business management.

\section{- Sports Facility Management and Operation}

This subject is designed to prepare students in managing operating procedures of different facilities. It also considers the possibilities and the impact of the latest technologies, as well as different operating strategies and sports venues.

\section{- Marketing and Communications}

It aims to strengthen the knowledge of strategic and operational marketing. In this module, students analyze, justify and prescribe the best tools for marketing research, segmentation and market positioning and operational planning of the marketing tools and their implementation and control.

\section{- Managerial Skills and Human Resources}

The importance of acquiring skills and management training is a key to career success. The objective of this subject is to empower the students with managerial skills. It provides students with essential tools for the effective management of the work teams.

Moreover, there exist specialization branches, which have specific objectives in order to provide knowledge about the legal, social responsibility and business creation, or to deepen into the already acquired concepts of operations and marketing, but related to the business of different sports.

\section{- Internship}

This activity gives students the opportunity to apply the acquired knowledge and experience in order to confirm the viability of their actions and procedures in a real environment. These exercises may be done in a company of any sector and in any decision area and even in other nonprofit institutions or public companies

\section{- Master's Thesis}

This subject includes a final project where the student has work deeply in a global way, with all the concepts and skills developed along the Master.

\section{THE PEDAGOGICAL MODEL FOR VIRTUAL SUBJECTS}

It seems common to think that virtual mode provides the flexibility that adult students need, who must combine work, family and studies (Bates and Sangrá, 2011: 19): "There is strong evidence that e-learning has been successful in increasing flexibility and thus making post secondary education more accessible". There are many institutions of higher education that are delivering their studies through a virtual model. In this context, educational research carried out in this area has shown its effectiveness in student's learning. Specifically, the results of 43 studies with adult students concluded that learning through the online mode is effective for both college students and graduate students and professionals in a wide variety of academic and professional studies (Means, Toyama, Murphy, Bakia and Jones, k., 2010).

The educational model of Universidad Europea has the assumption of being sensitive as an institution to the needs of society, which necessarily implies an orientation towards adults. Thus, since academic year 2010-2011, our University offers a series of on line undergraduate and graduate programs that complement the on campus offer. Most of these programs are basically enrolled by working adults, who want to enhance their professional career by starting full-time or part-time university studies.

In order to allow a greater flexibility, students can decide in three or four academic periods the number of subjects they want to study (maximum student workload of 40 hours per week) and the teaching modality (students may take all subjects online, all subjects campus-based, or some subjects online and some campus-based). According to this hybrid format, our University has designed a pedagogical model for virtual subjects, based on different learning and teaching theories ${ }^{1}$, in order to ensure the quality of the educational process.

Only until a few years ago, most of the virtual learning environments have been based on behavioral and cognitive pedagogical approaches, so that the student could achieve previously planned learning objectives. At present, a constructivist approach is increasingly being used for online courses because it helps students to better develop professional skills and face multiple realities (Guardia and Sangrà, 2005). Nevertheless, there is not a single and best pedagogic model. According to Gros (1997), any learning and teaching theory is partial and insufficient to explain all the learning situations. 
Thus, our pedagogical model 2 has been designed as an eclectic model, which can be adapted to different situations and contexts of teaching-learning, according to the characteristics of each subject: "What might be more effective for novice learners encountering a complex body of knowledge for the first time, would not be effective, efficient or simulating for a learner who is more familiar with the content" (Ermert and Newby, 67: 1993).

These authors argue that the acquisition of introductory knowledge is best achieved through objectivist approaches (behavioral and/or cognitive) but they suggest a transition to the constructivist approach to the extent that the students improve their knowledge.

\section{A. The principles of our pedagogical model}

Our pedagogical model is based on some principles that we consider basic to succeed in the teaching-learning process in a virtual learning environment. These are the following:

\section{- Motivation}

Usually, the student who chooses the online mode does it encouraged by the flexibility that it offers, but may also have (mainly in the case of adult workers) a goal or personal circumstances and/or professionals who motivate him strongly towards the study.

\section{- The subject schedule as an instrument for} autonomous learning

The subject schedule in virtual teaching is one of the fundamental tools for the development of the independent student work (Holmberg, 1985), which also allows him to control his learning pace. Thus, there must have learning guides showing the planning that will be followed in the subject. Moreover, the lecturer must clarify the sequence with which the activities and their timing will be carried out.

The learning sequence must be coherent with the elements that compose its didactic design (objectives, contents, learning resources, assessment) and to allow the student to follow the course and being aware of his learning.

\section{- Meaningful of learning materials}

It is very important to activate and maintain the curiosity and motivation of the student throughout the learning process (Duart, 2000). Thus, the learning materials:

- Must be relevant for the student and to consider his/her expectations, need, and previous knowledge.

- Must be structured and sequenced in order to be meaningful and the student relate new learning material with their prior knowledge (use of summaries, synthesis, and advance organizers).

- Must include a variety of learning resources in order to allow adaptation to different learning styles.

- The sequencing of the contents must be carried out according to the nature of each subject.

\section{- Interaction}

Our pedagogical model includes the interaction between lecture-student and also among the students. The feeling that there exist a personal relationship between students and lectures encourages the student's motivation. Moreover, collaboration among students fosters the joint construction of knowledge. In this context, the lecturer must be a facilitator and a guide throughout the learning process.

\section{- Useful activities}

There must be included meaningful activities for the students. The design of activities must take into account different learning strategies depending on the type of knowledge that students need to acquire (mastery of basics concepts, to apply facts and rules, etc.).

\section{- Continuous assessment}

The continuous assessment throughout a set of guided activities increases the student's motivation, because it allows the student to be aware of his/her improvement. Thus, the activities should be scheduled from the beginning of the course and lecturer must provide frequent feedback to the student. Moreover, self-evaluation activities allow the self-regulation of the learning process.

\section{B. The structure for virtual subjects}

Our full time online degrees are structured in 60 ECTS credits per academic year, which, at the same time, are organized in 10 subjects of 6 ECTS credits. Each 6 ECTS credit subject (150 hours of student workload) is structured in 6 Learning Units and each one of them corresponds to 1 ECTS credit (25 hours of student workload). Each Learning Unit is usually taught in two weeks, even though this time may vary depending on the academic calendar. The following chart shows an estimation of the student workload in a standard subject of theoretical and practical content:

TABLE I.

ESTIMATION OF STUDENT WORKLOAD IN AN ONLINE SUBJECT.

\begin{tabular}{|l|c|}
\hline \multicolumn{1}{|c|}{ Subject (6 ECTS) } & Student workload (hours) \\
\hline Individual activity (2 ECTS) & 50 \\
\hline Collaborative work (1 ECTS) & 25 \\
\hline Assessment and tutoring (1 ECTS) & 25 \\
\hline Independent study (2 ECTS) & 50 \\
\hline Total & 150 \\
\hline
\end{tabular}

The individual activity (2 ECTS) encompasses the reading of lessons and the view/ reading of additional resources, such as videos, articles, data bases or events recording related to the subject. Moreover, every subject includes an interactive multimedia resource (simulations of applications, cases, decision trees, etc.), which allow the students to widen or reinforce certain concepts or procedures. In some Learning Units, students must attend a virtual seminar (an online class in real time), carried out through a web conference tool. Finally, as a part of the individual activity, students will apply what they have learnt through different tasks (case studies, problems, reports, projects, summaries, etc.).

One of the most important principles in our pedagogical model is the interaction between lecturer and students as well as amongst students. In some tasks, students have to 
work together in the resolution of case studies, problems, projects, etc., in order to achieve a common goal. In the collaborative work (1 ECTS), students should communicate with each other through different tools such as a forum, chat and web conference. In our pedagogical model teaching must be group-paced and the main role of the lecturer is to guide the students through the learning process. For that reason, tutoring has a specific weight in our model (1 ECTS), and not only is it used in case students need to solve questions related to the contents or to the tasks, but also in order to correct tasks or to reinforce and enrich student's knowledge. Finally, independent study (2 ECTS) incorporates the time students spend working in an autonomous manner in order to achieve the learning results.

\section{THE E-LEARNING PRODUCT: HOW THE SUBJECT IS ORGANIZED}

The e-learning product is based on the skeleton provided by the pedagogical model. Delivered by an open source learning management system (LMS), the eLearning product is clearly divided in three areas: one with all the general pedagogical elements, being the Learning Guide, the Concept Map, the Presentation and the Multimedia resource; another with all the general communication elements, being the Virtual Class, Technical Forum and General Forum; and another area where the 6 Learning Units are deployed, within an "open area" where the lecturer can upload files as needed during the teaching of the subject.

In the next section we present the different elements of each of these areas:

\section{A. First area: The e-learning general documents}

In the first area of the e-learning product, the Learning Guide is available and details the main rules for studying the subject: schedule, assessment, additional bibliography, etc. The Concept Map shows all the conceptual connections developed in the subject, so as to help the student to have an overview of the subject. It also prepares the students for the class, as it helps them to understand what they are going to study, and in some sense, in which order they are going to do it.

The Presentation is a short video that is used to motivate, to break pre ideas, and to open the mind of the students in order to help them to attend the subject with a different perspective.

The last element in this area is an interactive multimedia resource. This multimedia element is strongly connected to the content developed in the subject, offering more content - that is not easy to explain just in words-, or to a study case that they have to solve. What offers to the students a virtual situation where they interact in a scenario and are able to manage concepts, ideas, examples, take decisions, etc. Also, in the case of being involved a study case to the multimedia, it offers information to be used later to develop correctly the activity linked to it.

For example, in the case of the subject "Specialization in Operation of Sports Facilities", this element represents a ski resort. It describes all the characteristics and attributes of the place and its natural resources. The content offers clues to the students in order to drive them to explore the scenario, identifying which attributes and services already exist in the ski resort and can be used (out of the ski season) to cover other sport tourism and events, like fresh water diving, mountain bike, climbing, paragliding, kayaking, awards ceremonies, etc.

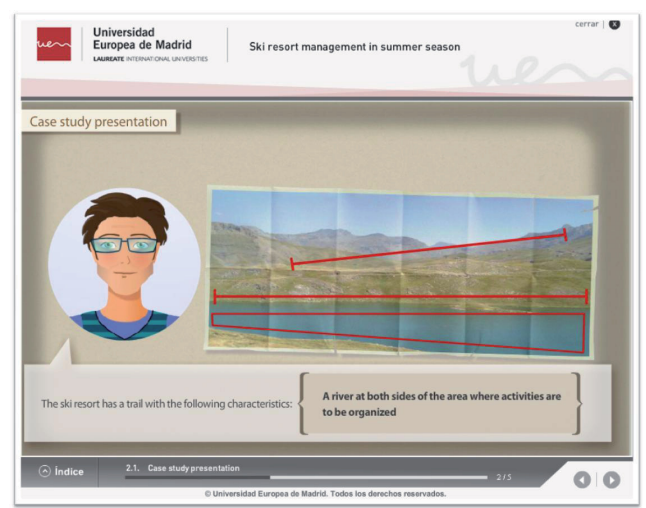

Image 1. Screenshot Multimedia resource

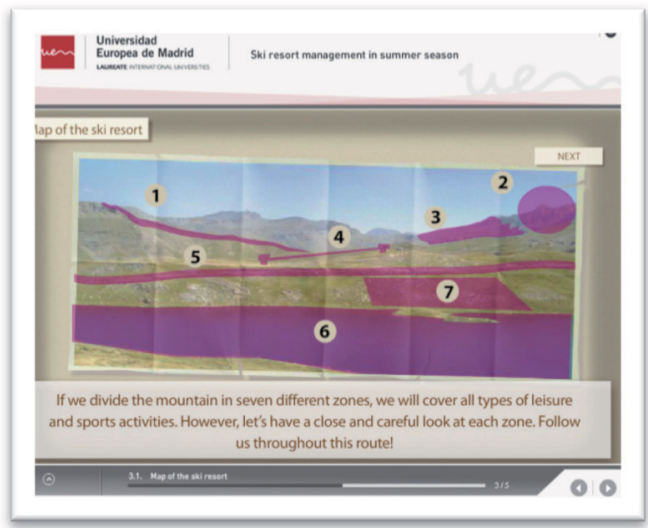

Image 2. Screenshot Multimedia resource

\section{B. Second area: The communication tools}

In the second area all the communications tools are placed. The professor uses the General Forum to communicate with the students about general issues of the course: dates for the virtual seminars, general organizational rules of the subject, etc.

The technical Forum is used by the students to get in touch with the Program Assistant, in case of having trouble in the Virtual Campus. It is important to mention that all the students have a short course before starting the studies on the Virtual Campus about how to study a program under the Universidad Personal model. This short course shows not only the tools, but the way of allocating time for studying and how to achieve the best results.

The Virtual Class, a web conference tool, is used by the lecturer to deliver master classes, solving problems or to offer to the students a seminar with a guest; someone important in the field of the subject. It can be used as well to interact with the students and discuss a topic related to the subject, or even to evaluate a group activity, as the executive presentation of a delivered report.

Each subject has as standard three virtual sessions, although it can be as many as needed along the teaching period. Is important to mention here, that all the virtual classes can be recorded with the web conference tool, therefore, they can be uploaded at the open area to be 
accessed by all those who have not been present at the web conference, or just want to have another look to it.

\section{Third area: The Learning Units, activities, pre and post test and open space}

In the third area the student has the access to the 6 Learning Units and the open area. All Learning Unit are design following the same structure, although there can be differences in the number of the elements placed in the different sections of each Unit. The structure was build to facilitate the students the identification of the different sections for communicating with the lecturer, the Program Assistant and the other students, and study along the different subjects of the program. To design the structure of the Units, were followed the indications of the pedagogical team of the University under the European Higher Education Area (EHEA) suggestions.

Our objective was, on the one hand, to offer to the lecturers a sharp space, where it could be easy to drive, in a smooth way, the students through the subject and, on the other hand, to assign easily a range of milestones in order to complete the subject. This was also to avoid the models were the learning is assessed just in a final exam. Thanks to this, one can assure that the students are completing the learning by little steps, which helps them to succeed on the achievement of the learning results, with even better performance than the face to face students (Redondo, 2012).

Behind this model of design it exists also the clear aim on not having to learn constantly how to browse the subjects, as they are always based on the same subdivisions.

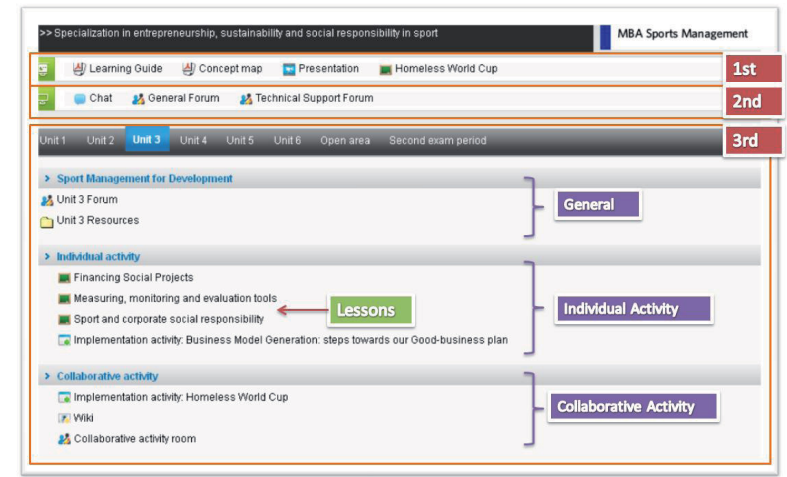

Image 3. Screenshot of structure of a virtual subject

All learning Units have at least one activity associated, it can be individual or collaborative. Likewise, all subjects have a previous and post assessment test. The previous test appears to the student just before the first lesson, at the first Learning Unit space. It is normally used by the lecturers to check previous concepts of the students, or to know the level of knowledge of the group-class, and even to motivate them in the study of the subject they are going to start. The final test is located at the end of the last lesson of the sixth Learning Unit. This normally represents a percentage of the total grade of the subject. It is used to check the level of general knowledge of the students by the end of the subject. The final test is also used as a control tool to ensure the coherence between the results obtained by the student in it and the grades on the activities delivered along the subject. In case of doubt, a face to face test (e.g. exam or presentation) can be requested to the student.

Also in this third area, the lecturers have a specific space to be used during the life of the subject: the Open Area,

where the lecturers can upload all those files requested for the teaching during the delivery of teaching. This space exists because the whole subject is designed, developed and upload in the system before the teaching. So, the lecturer finds deployed the whole subject before the teaching starts. For this reason, lecturers need a space, easy to identify by all the participants, where they can upload resources that are need at the last minute. For example, all virtual seminars delivered through the course are uploaded in this space and all students can watch them asynchronously. Likewise, if the lecturer needs to upload an extra activity (i.e. for a student that is joining the course later than the rest of the group), he/she can deliver it through this space. Additionally, a big variety of teaching resources designed by the lecturer can be uploaded in this space. And, as we commented before, at the end of the teaching, a satisfaction survey will be uploaded to be complete by the students. In this survey, they will assess their level of satisfaction with the learning, the content and the lecturer.

\section{THE LEARNING UNITS STRUCTURE}

The Learning Units, as the rest of elements of the subject, are always free to be accessed by the students. However, the Learning Guide shows the schedule of activities covering a calendar of 12 weeks as standard. Thanks to this, the students can decide their own learning pace, when and how access the content. Nevertheless, they will have to accomplish the deliveries on the date they were planed since the beginning at the Learning Guide by the lecturer.

The structure in the Unit is organized in three sections: the general area, the individual activity area and the collaborative activity area ${ }^{1}$.

\section{A. General area}

In the general area the students have a specific Forum, where they can communicate their questions about the content or the activities with the lecturer and other students. It also has a resources folder, where the student can access additional material related to the topic developed in the Learning Unit or to carry out the activity linked to it. All the material shown in the subjects must always accomplish the Copy Right laws and they are only offered only if the University has the right to do it so.

\section{B. Individual activity area}

Below the general area, the student has deployed the lessons, normally four, and the individual assessment in the "individual activity area". The Instructional Design theory (Merrill, 1994) is the core of our model of product for the lessons as it is explained later.

Each lesson is encapsulated as an SCORM file to help the students to access the same point where they left the lesson, and to the lecturers to know how the students are progressing.

\footnotetext{
It can be the case though, that in some Units would be only individual
} activity or only collaborative activity. 
Each lesson can be browsed in multiple devices (laptop, mobile, etc.). It tries to cover 45 minutes of comprehensive reading, therefore each lesson is developed around 14 screens. Each screen provides two levels of reading: the global idea and the specific details or examples of it. It is prearranged this way with the purpose of covering both types of styles on reading/studying of our students: those who prefer to receive first the idea and then go back and restart, going into a deeper level of reading on the second round; and those who prefer to read it deeply since the beginning.

Following the same philosophy, each lesson can be browsed from two different points. It has an index at the left with the titles of all the screens up to the end of the lesson. The student can click on them, and go straight to the content they want without having to pass all the screens since the beginning. This is especially helpful in a review mode. There is also the option of moving sequentially, screen after screen.

Each lesson follows the structure of a presentation of the content and main specific objectives to be covered by the end of the lesson; the main area of development of the content with 2 self-assessment activities and a final summary of contents.

All lessons share the same framework of design and have two permanent icons: one to the materials and one to the help. The materials will have always at least the PDF of the lesson. It is a document formatted to be printed, where the students can add notes, highlight ideas, etc. In some lessons this area stores the additional resources to complete the lesson, like specific diagrams too big to be shown in the screen, Law texts, etc. The help is a "users help", where all the information about how to browse the lessons is explained.

As we commented before, the student can browse any of the lessons of the subject at any time. That means there are no pre-requisites to access to the lessons of the different Learning Units. This behavior is part of the pedagogical requisites demanded by the pedagogical team of the University. To assure that the main objective of the Learning Unit is being achieved by the students, the authors of the content (the lecturers) invest a long period of time on the design stage. Just to assure that all the specific objectives pursued on the lessons, are being measured on the activity that is covering the assessment of the Learning Unit.

So, after the four lessons of the Learning Unit the student has the link to the individual activity. The activity always implies the upload of a report or a presentation that the student has to develop with all the resources offered in the Learning Unit and also with information that they have to be able to find by themselves on the Internet, at the Library, etc. Those activities can involve as well reading a case of study, solving a problem based learning activity, proposing an action plan, etc.

\section{Collaborative activity area}

Some of the Learning Units can also have collaborative activities. In this case, the collaborative area of the Students Group will be just below the individual area of the student. The Student groups are formed by a range of members from 3 to 5 maximum. In this area the group will have the activity to develop, a "working space" to leave messages, documents, etc. and it can have as well other tools to be used, such as wikis. The lecturers access to those "working spaces" and track the records of each member of the group, to be able to assess the participations of all members of the group in the activity. For this reason, the students are encouraged to register all their communications inside the Virtual Campus.

\section{NEXT STEPS}

Modeled on Universidad Europea de Madrid work performed for all programs, improvements continue to be implemented to answer the needs of students and teaching requirements. In this line of development, currently the MBA Master's Degree in Sports Management is being extended to use synchronous collaboration tools (web conference) in the area of collaborative work, providing more elements to overcome difficulties related to collaborative activities on virtual environments, among others.

\section{REFERENCES}

[1] A. W, Bates \& A. Sangrà, "Managing technology in higher education: strategies for transforming teaching and learning". San Francisco, C.A, Wiley Publishers, 2011.

[2] B, Gros, "Diseños y programas educativos, Pautas pedagógicas para la elaboración de software". Barcelona, Ariel, 1997.

[3] B, Holmberg, B., "Educación a distancia: situación y perspectivas". Buenos Aires, Kapelusz, 1985.

[4] B, Means, Y. Toyama, R,, Murphy, R., Bakia, M., y K. Jones, "Evaluation of Evidence-Based Practices in Online Learning. A Meta-Analysis and Review of Online Learning Studies". Washinghton, D.C., U.S. Department of Education, 2010. Available: http://www2.ed.gov/rschstat/eval/tech/evidencebasedpractices/finalreport.pdf

[5] G, Rodriguez; J.I., Mayorga; A. Merino, M. Garrido, \& M. Fernandez, "Hábitos deportivos de la población de la Comunidad de Madrid". Dirección General de Deportes CAM, 2005.

[6] J.M., Duart, "La motivación como interacción entre el hombre y el ordenador en los procesos de formación no presencial". In Aprender en la virtualidad, J.M. Duart y A. Sangrà, Eds. Barcelona, Gedisa, 2000, pp. 87-112.

[7] L. Guardia y A. Sangrá, "Diseño instruccional y objetos de aprendizaje; hacia un modelo para el diseño de actividades de evaluación del aprendizaje on-line". RED. Revista de Educación a Distancia, 2, 2005, pp. 4-14. Available: http://www.um.es/ead/red/M4

[8] M.D, Merrill, "Instructional Design Theory". Englewood Cliffs, NJ: Educational Technology Publications, 1994.

[9] P.A, Ermert \& T.J. Newby, "Behaviorism, cognitivism, constructivism: comparing critical features from an instructional design perspective". Performance Improvement Quarterly, 4, Vol. 6, 1993, pp. 50-72.

[10] S, Redondo, "Evaluación de la aplicación del modelo pedagógico UEM Personal a estudios universitarios de grado y postgrado en modalidad online". Doctoral thesis, Universidad Europea de Madrid, 2012

\section{AUTHORS}

Sara Redondo, Ana María Villalba, and Álvaro Merino Jiménez are with Universidad Europea Madrid, Madrid, Spain.

Submitted 31 January 2013. Published as re-submitted by the authors 8 August 2013. 